\title{
Effects of coordinated strategies on product and process R\&D
}

\author{
Elena Cefis · Stephanie Rosenkranz • Utz Weitzel
}

Received: 6 August 2007 / Accepted: 6 August 2008 / Published online: 10 September 2008

(C) The Author(s) 2008. This article is published with open access at Springerlink.com

\begin{abstract}
Using a game theoretical model on firms' simultaneous investments in product and process $R \& D$, we advance and empirically test hypotheses on the role of externalities on the optimal R\&D portfolio of cooperating firms and independently competing firms. We use Community Innovation Survey data on 3,696 Italian manufacturing firms. In line with our model we find that members of a group of firms invest significantly more into product, process, and aggregate R\&D than independent firms. Further, their R\&D portfolios tend to show a higher product versus process ratio. However, with regard to R\&D performance and efficiency we find that independent firms are superior.
\end{abstract}

Keywords Coordination $\cdot \mathrm{R} \& \mathrm{D} \cdot$ Innovation $\cdot$ Efficiency $\cdot$ Cost reduction $\cdot$ Product differentiation

JEL Classification $\quad \mathrm{C} 72 \cdot \mathrm{L} 1 \cdot \mathrm{L} 13 \cdot \mathrm{O} 32$

\section{Introduction}

Despite a long history of empirical studies on corporate $R \& D$ and a rich theoretical foundation of joint $R \& D$ decision-making, there is little empirical research on

E. Cefis

University of Bergamo, Bergamo, Italy

E. Cefis $\cdot$ S. Rosenkranz $(\varangle) \cdot$ U. Weitzel

Utrecht School of Economics, Utrecht University, Janskerkhof 12, 3512 BL Utrecht, The Netherlands

e-mail: s.rosenkranz@econ.uu.nl

S. Rosenkranz

CEPR, London, UK 
the relationship between product and process $\mathrm{R} \& \mathrm{D}$ in combination with coordinated strategies. Most studies that empirically analyse the effects of coordinated strategies, for instance, in acquisitions, joint ventures, or alliances, refer to innovative activities in general, regardless whether these are focused on processes or products. ${ }^{1}$ We argue that exactly this distinction between product and process R\&D is important to fully understand the effects of coordinated strategies that take place in groups of firms, as opposed to individually competing firms. If product and process innovations have different externalities, the internalisation of these effects via joint decision-making may result in a different $\mathrm{R} \& \mathrm{D}$ portfolio than that of independently competing firms.

In this paper we develop a generalized version of the model of Rosenkranz (2003) and deduct testable hypotheses on the basis of which we empirically analyse the level and the relative importance of process and product $R \& D$ in firms that belong to a group and in independently competing firms. The data also allow us to test for respective differences in R\&D performance and efficiency, both, on an aggregate level and for product and process R\&D separately. In summary, the central questions addressed in our analysis are: does the theoretical concept of product and process externalities find empirical support? Do firms that are part of a group invest relatively more in product or process $R \& D$ than independent firms? Do firms with coordinated strategies show a different level of aggregate $R \& D$, performance, and efficiency?

For empirical testing we use data from the first Italian Community Innovation Survey (CIS) on 18,467 firms across all manufacturing industries and size groups (over 19 employees) which cover the period 1990-1992. We construct two samples, one with independent firms and one with firms that consider themselves to be a member of a group. Based on the questionnaire of the CIS, the claim of group membership can be interpreted as the willingness to (at least partially) coordinate innovation strategies and decisions within organizational structures of shared decision control.

The empirical results support the propositions of the formal analysis in various aspects. Firms that are part of a group do invest differently in R\&D than independent firms. Our multivariate results show that independent firms invest less into product, process, and aggregate R\&D than firms that are part of a group. Moreover, bivariate analyses indicate that coordinated strategies are associated with a higher product vs. process ratio in the R\&D portfolio. However, the empirical results also show that independent firms are superior with regard to R\&D efficiency, since coordinated strategies lead to a comparatively worse $\mathrm{R} \& \mathrm{D}$ performance.

The contribution of this paper to the current state of research is threefold: first, this study provides some empirical support for the theoretical notion that joint R\&D strategies may not only be influenced by efficiency aspects, but also by externalities. Second, the paper sheds some light on the scarcely studied relationship between product and process R\&D in coordinated strategies. Third, the study presents empirical results on aggregate $R \& D$ performance and efficiency in coordinated strategies.

\footnotetext{
1 Throughout this paper we define 'acquisition' as the consummated purchase of any kind of equity interest (minority or majority) in another company. In contrast to a merger we assume that both companies remain a legal entity. The term 'alliance' includes equity alliances (cross-holdings) as well as contractual alliances (non-equity) between two companies, while 'joint venture' refers to new legal entity that is funded (50:50) by two parent firms.
} 
The paper is organised as follows: Sect. 2 provides a literature overview. Section 3 presents the game theoretic model including the formulation of testable hypotheses. In Sect. 4 we describe the sample and the variables. The econometric analysis, its results and implications are presented in Sect. 5, followed by concluding remarks in Sect. 6.

\section{Literature review}

Generally, we can distinguish three strands of previous research in this area: (i) studies on product and process R\&D in independently competing firms; (ii) studies on coordinated strategies (in acquisitions, joint ventures, and alliances) and aggregate $\mathrm{R} \& \mathrm{D}$; and (iii) studies on product and process $\mathrm{R} \& \mathrm{D}$ and coordinated strategies in joint ventures.

(i) From an individual firm's perspective, innovation strategies often focus either on process innovation or on product innovation. Porter (1980) argues that a firm's strategic position within a broad-scope market is determined by one of two fundamental options: offer the lowest price or differentiate your products. Although Porter (1980) considers the two strategies of cost reduction and differentiation to be basically incompatible, Miller and Friesen (1986a,b) make a strong case that a firm's advantage is rarely based entirely on costs or product differentiation and that both dimensions ought to be modelled and studied jointly. Such a less polarised world suggests that there exists an optimal mix in firms' R\&D portfolio, i.e. an optimal level of investment in process $\mathrm{R} \& \mathrm{D}$ (cost reduction) and in product $\mathrm{R} \& \mathrm{D}$ (product differentiation). This notion is also widely accepted in industrial dynamics, which can be traced back to the seminal work of Abernathy and Utterback $(1979,1982)$, who introduced a technological lifecycle model of industries. Klepper (1996) formalizes the concept and identifies the role of firm innovative capabilities and size in conditioning R\&D spending. A number of theoretical and empirical studies usefully elaborate on this concept, but without specific focus on the strategic interdependence or coordination of firms' R\&D strategies. ${ }^{2}$

From a sector perspective, Pavitt (1984) proposed a taxonomy that inter alia distinguishes between product and process oriented sectors, based on a statistical analysis of more than 2000 innovations that have taken place in Britain after the second Word War. The taxonomy builds upon the interaction of several market, technology and innovation characteristics, like the sources of technology, the type of users, the objective and the trajectory of innovations. Pavitt (1984) identifies the following four different categories of firms according to the criteria used. Supplier dominated firms, typically small firms, for which innovation comes through equipment and machinery acquired from innovative suppliers. In this sector, process innovation dominates. Specialised suppliers firms, for which the main activity is the production of innovative equipment and instrumentation. Here, product innovation is dominant. Science based firms, mainly chemical and electronic firms that invest heavily in internal R\&D and production engineering. In this sector there is a balance between product and process innovation.

\footnotetext{
2 See, e.g. Agarwal and Audretsch (2001), Duranton (2000), Yin and Zuscovitch (1998), Tushman and Anderson (1986), Anderson and Tushman (1990), Klepper and Graddy (1990), and Suarez and Utterback (1991).
} 
Scale intensive firms that generally produce bulk materials and assembly. They mainly pursue process innovations and their sources of technology are often their R\&D and engineering departments as well as external sources like science-based firms. In this paper we will include Pavitt's (1984) taxonomy in the econometric specification to account for sectoral patterns with regard to product and process innovations.

(ii) In the current debate whether coordinated R\&D strategies, especially in equity alliances and acquisitions, ${ }^{3}$ are associated with higher or lower aggregate levels of innovation, empirical results are mixed and relatively limited in depth and breadth. This might be connected to the fact that, apart from industrial organisational models on joint ventures (discussed below), the theoretical literature largely remains mute on this issue. ${ }^{4}$ Some empirical studies on the financial and economic performance of acquisitions and alliances consider the consequences on firms' technological activities. However, the results with regard to the effect of coordinated efforts on innovation levels turn out to be heterogeneous and difficult to compare: empirical analyses in industrial organization reach no consensus, but tentatively point towards a more positive relationship (Röller et al. 2001; also see Cohen and Levin 1989; Scherer 1992, for useful reviews). Larger studies in the field of financial economics and corporate control are rather undecided, but tend to support the notion of a neutral or negative impact (Hall 1990, 1999; Ravenscraft and Scherer 1987; Hitt et al. 1991, 1996; Blonigen and Taylor 2000). In contrast to that, several smaller in depth studies on acquisitions and joint ventures convey a more positive outlook on innovative investment and performance (Gugler and Siebert 2004; Ahuja and Katila 2001; Cassiman et al. 2003; Adams and Marcu 2004).

One reason why the empirical results are so mixed may be that innovation studies use a multitude of measurements. These range from R\&D spending, total innovation expenditure, intangible assets, patent applications, approved patents, patent citations, new product announcements, to shares in sales taken by imitative and by innovative products. ${ }^{5}$ In particular, many studies focus either on innovation input (e.g. R\&D spending) or on innovation performance (e.g. patents). Any conclusion for innovative behaviour in general then implicitly assumes a constant R\&D efficiency. ${ }^{6}$ However, while $R \& D$ investment may be cut, joint $R \& D$ performance or output can still be unchanged or even higher. Even if efficiency gains reduce investment in R\&D (e.g. through elimination of duplication, or economies of scale/scope), the internalisation of positive externalities increase marginal returns to innovation and provide an incentive to invest more in R\&D after the coordination of strategies via an acquisition, joint venture or alliance. For a thorough understanding, we therefore include such externalities in our analysis. Another reason why empirical studies on aggregate

\footnotetext{
3 See Katz and Shelanski (2004) for an example of this debate about the US antitrust and merger policy.

4 For a comprehensive survey see Cassiman et al. (2003).

5 For studies on the differences and similarities between these measures and a review of the debate please refer to Brouwer and Kleinknecht (1999), Kleinknecht et al. (2002) and Hagedoorn and Cloodt (2003).

6 As also mentioned previously (see, e.g., Hinloopen 2003), when innovation measures are ill defined this can lead to some additional confusion whether terms like 'innovation' and 'innovation level' refer to R\&D investment/spending (input) or performance (output).
} 
innovation levels are mixed may lie in the fact that they do not control for different effects of product and process R\&D, as argued in our model.

(iii) When we combine coordinated $\mathrm{R} \& \mathrm{D}$ strategies with the distinction between product and process $R \& D$, a survey of the literature quickly reveals that most studies are theoretical, mainly published in the field of industrial organisation. Initiated by D'Aspremont and Jacquemin (1988) these studies focus on the internalisation of positive or negative externalities through research joint ventures (RJVs) and their comparative static effects with regard to process and product R\&D spending (De Bondt and Veugelers 1991; De Bondt 1996; Bonnano and Haworth 1998). Process innovations can be seen as negative externalities, since lower prices force competitors to either 'wastefully' invest in corresponding cost reductions or accept lower profits due to the 'business stealing effect'. However, by forming an RJV or acquiring a firm, this negative externality can be internalised and avoided. Technological spillovers, on the other hand, can be seen as positive externalities, since competitors profit from the know-how of others without own investment. When coordinating R\&D strategies in RJVs, the returns lost to the innovator due to unprotected spillovers are (partially) captured and, depending on the magnitude of internalisation, lead to higher incentives to innovate.

Most of the RJV literature addresses positive externalities only in the context of technological spillovers. However, horizontal product differentiation can have the same (positive) effect when it reduces the substitutability of competitors' products and increases consumers' willingness to pay. ${ }^{7}$ This leads to less direct competition and higher profits. An internalisation of horizontal differentiation captures the positive externalities of consumers' increased willingness to pay, which would otherwise be lost to competition. By modelling horizontal and vertical differentiation efforts in a specific strategic setting, Rosenkranz (2003) shows in a formal model that the formation of RJVs changes the optimal combination of product and process R\&D.

On the basis of prior research we can thus assume for our analysis: provided that product and process $R \& D$ have different externalities, coordinated strategies should lead to an adjustment of the optimal mix of innovation investments since they allow for the internalisation of different degrees of positive and negative external effects. The analysis of these effects would explain changes in not only the ratio of product vs. process $R \& D$ (i.e. the $R \& D$ portfolio), but also the level of spending on product and process $R \& D$.

\footnotetext{
7 Much in line with Eswaran and Gallini (1996) this refers to horizontal innovations where no new product is automatically superior in the absolute sense. They simply have more distinctive characteristics, which generally increase consumers' valuation. An extreme example for such horizontal innovations in alliances is a multi purpose vehicle (MPV) dubbed 'Eurovan', which is produced by a joint venture of PSA Peugeot/ Citroën and Fiat/Lancia. For each of the companies involved a technically identical van with slightly differentiated bodies is produced and sold under the brand names Peugeot 806, Citroën Evasion, Fiat Ulysse, and Lancia Zeta. (For the second generation, which is produced since 2002, the names were partially changed to Peugeot 807, Citroën C8, Fiat Ulysse, and Lancia Phedra.) Other examples can be frequently found within automotive groups. In the Volkswagen group, for instance, Seat, Audi, Škoda, and Volkswagen build some of their cars on identical chassis platforms and with nearly identical technical characteristics, but these cars are nevertheless differentiated by interior and exterior design, branding and positioning.
} 


\section{Formal analysis and hypotheses}

We consider a duopolistic industry, consisting of two firms $i, j$ that produce quantities $x_{i}$ and $x_{j} .{ }^{8}$ The two firms operate under constant returns to scale. Firms' unit costs of production are given by $c_{i}$ and $c_{j}$ with $c_{i}, c_{j} \in[0, a]$, which can be chosen through R\&D investment before the market opens. The product characteristics which determine the degree of product substitutability given by $\delta:=\delta_{i}+\delta_{j}$ can also be influenced by the firms $i, j$ through $\mathrm{R} \& \mathrm{D}$ investment in $\delta_{i}$, and $\delta_{j}$, respectively, with $\delta_{i}, \delta_{j} \in\left[0, \frac{1}{2}\right]$.

The cost function for $\mathrm{R} \& \mathrm{D}$ is the same for both firms and is described by $K\left(c_{i}\right)+$ $G\left(\delta_{i}\right)$ with $K^{\prime}<0, G^{\prime}<0$ and $K^{\prime \prime}>0, G^{\prime \prime}>0$. The higher the marginal costs and the lower product differentiation the lower is the needed research investment. Note that for simplicity we abstract from possible economies of scope between the two kinds of investments. ${ }^{9}$ We assume that there exists an initial level of costs $c^{o}$ with $K\left(c^{o}\right)=0$ for all $c_{i} \geq c^{o}$ and $\lim _{c_{i} \rightarrow c^{o}} K\left(c_{i}\right)=0$ and an initial level of product differentiation $\delta_{i}^{o} \leq \frac{1}{2}$ with $G\left(\delta_{i}^{o}\right)=0$ for all $\delta_{i} \geq \delta_{i}^{o}$ and $\lim _{\delta_{i} \rightarrow \delta_{i}^{o}} G\left(\delta_{i}\right)=0$. Further, (to guarantee interior solutions) we impose that $\lim _{c_{i} \rightarrow 0} K\left(c_{i}\right)=\infty$ as well as $\lim _{\delta_{i} \rightarrow 0}$ $G\left(\delta_{i}\right)=\infty$.

Firms play a non-cooperative two-stage game under complete information. In the first stage, they decide on their marginal costs by investing in a research project generating a process innovation. Simultaneously, they decide on the optimal degree of product differentiation by investing in another research project generating a product innovation. In the second stage, firms choose quantities. Anticipating the outcome of the stage-two game as $x_{i}^{*}\left(c_{i}, c_{j}, \delta_{i}, \delta_{j}\right)$ and $x_{j}^{*}\left(c_{i}, c_{j}, \delta_{i}, \delta_{j}\right)$, firms choose optimal R\&D portfolios. ${ }^{10}$ Possible R\&D projects in such a portfolio are targeted at process innovation and at product innovation. Through the former they choose marginal costs of production and through the latter they choose a degree of product differentiation. Firms' strategies are $\left(c_{\nu}, \delta_{v}\right) \in R^{2}$, with $c_{\nu} \in\left[0, c^{o}\right]$ and $\delta_{v} \in\left[0, \delta_{v}^{o}\right]$ with $v=i, j$. In equilibrium a firm's optimal $R \& D$ portfolio is

$$
\left(c_{\nu}, \delta_{v}\right) \in \underset{c_{\nu}, \delta_{v}}{\arg \max }\left\{\Pi_{v}=\pi_{v}^{*}\left(c_{\nu}, \delta_{v}\right)-K\left(c_{\nu}\right)-G\left(\delta_{v}\right)\right\}
$$

with $v=i, j$, where $\Pi_{\nu}$ denotes a firm's gross profit and $\pi_{v}$ a firm's profit net of R\&D costs.

\footnotetext{
8 The analysis generalises Rosenkranz (2003) as here no specific demand function is assumed.

${ }^{9}$ We consider this the benchmark case because, in principle, next to the here assumed independent cost functions, both economies of scope as well as diseconomies of scope are plausible. Their presence and sign depend on the product life cycle as well as the specificities of the product.

10 The assumption of complete information relates here to a situation in which the firms have a good understanding of the technologies and opportunities of other firms on the market. Firms nevertheless face strategic uncertainty as it is assumed that they choose simultaneously, thus in ignorance of the other firm's decision. Furthermore, the analysis could be extended to the more realistic situation in which the innovative activities themselves are characterised by uncertainty, by translating all output values into expected values, which would not alter our results qualitatively.
} 
Now suppose that firms jointly decide on their R\&D activities. For simplicity we assume that they remain competitors in the second stage of the game ${ }^{11}$ and operate under the constraint of identical investments. ${ }^{12}$ Assume that firms coordinate their strategies as to maximise joint profit but do not achieve efficiency gains because they utilise research technologies (both, for new products as well as processes) with decreasing returns. This rather unrealistic scenario is included in the analysis because it allows us to isolate the strategic effects of cooperative R\&D investment and the influence of efficiency gains.

Optimisation of firms' joint profit $\Pi_{k}=\Pi_{i}+\Pi_{j}$ with respect to $c_{i}$ leads to the following first order condition, which characterises optimal investment into process innovation under coordinated $\mathrm{R} \& \mathrm{D}$ strategies, for $c_{i}^{*}=c_{j}^{*}=c_{k}^{*}$ :

$$
\frac{\partial \Pi_{k}}{\partial c_{i}}=\frac{\partial \Pi_{i}}{\partial c_{i}}+\frac{\partial \Pi_{j}}{\partial c_{i}}=0,
$$

where $\Pi_{j_{c}}$ is the externality conferred by firm $i$ 's cost reduction on the profit of its rival $j .{ }^{13}$ Analogously, also the externality induced through product innovation by firm $i$ on the profit of firm $j$ is added to the competitive advantage externality that firm's R\&D effort has on its own profit through increasing the amount of differentiation of its competitor. Maximising joint profit with respect to the level of product differentiation $\delta_{i}$ yields the implicit function for optimal investment into product innovation, for $\delta_{i}^{*}=\delta_{j}^{*}=\delta_{k}^{*}$ :

$$
\frac{\partial \Pi_{k}}{\partial \delta_{i}}=\frac{\partial \Pi_{i}}{\partial \delta_{i}}+\frac{\partial \Pi_{j}}{\partial \delta_{i}}=0,
$$

Those externalities, positive or negative, are ignored when each firm chooses its R\&D expenditure so as to maximise its own profit. They are internalised when the firms coordinate their R\&D strategies. This makes the individual maximisation problems equivalent to the joint maximisation problem that would be solved, e.g. by a single decision maker for the two firms. In order to analyse the effect of the internalisation of externalities on the individual equilibrium values, we can measure the degree of internalisation by $\beta \in[0,1]$ and write the first-order conditions of the optimisation

\footnotetext{
11 This is a common assumption in the IO literature when firms coordinate research strategies. An analysis without such an assumption leads to not only qualitative identical, but altogether stronger results (see, e.g. Kamien et al. 1992).

12 In general, when the equal treatment constraint is not imposed R\&D cooperation always yields higher combined profits than R\&D competition because depending on the R\&D cost function firms have an incentive to reduce costs in one firm such that supplied quantity raises to the monopoly level and compensate the other firm via side payments for not producing (see Salant and Shaffer 1999; Amir et al. 2003). However, as emphasised in the literature, such solutions are hard to realise in practice.

13 Note that this externality will usually be negative in the absence of technological spillovers due to the business stealing effect, but might also become positive in case of strong spillovers.
} 
problems as

$$
\begin{aligned}
& \pi_{i_{c_{i}}}-K^{\prime}+\beta \pi_{j_{c_{i}}}=0, \text { and } \\
& \pi_{i_{\delta_{i}}}-G^{\prime}+\beta \pi_{j_{\delta_{i}}}=0 .
\end{aligned}
$$

Note that the equations represent the individual first order condition for $\beta=0$, while they represent the joint profit maximisation problem for $\beta=1$. By differentiating with respect to $\beta$, we can analyse the effects of adding these strategic terms to firms' firstorder conditions of profit maximisation (and thus the effect of internalised externalities on firms' investment incentives). Taking all variables as functions of $\beta$, differentiation of (1) and (2) with respect to $\beta$ yields:

$$
\begin{gathered}
\left(\pi_{i_{c_{i} c_{i}}}-K^{\prime \prime}+\beta \pi_{j_{c_{i} c_{i}}}\right) d c_{i}+\left(\pi_{i_{c_{i} \delta_{i}}}+\beta \pi_{j_{c_{i} \delta_{i}}}\right) d \delta_{i}+\pi_{j_{c_{i}}} d \beta=0, \\
\left(\pi_{i_{\delta_{i} c_{i}}}+\beta \pi_{j_{\delta_{i} c_{i}}}\right) d c_{i}+\left(\pi_{i_{\delta_{i} \delta_{i}}}-G^{\prime \prime}+\beta \pi_{j_{\delta_{i} \delta_{i}}}\right) d \delta_{i}+\pi_{j_{\delta_{i}}} d \beta=0 .
\end{gathered}
$$

Cramer's rule leads to:

$$
\begin{aligned}
& \operatorname{sign}\left(\frac{d c_{i}}{d \beta}\right)=\operatorname{sign}\left(-\left(\pi_{i_{\delta_{i} \delta_{i}}}-G^{\prime \prime}+\beta \pi_{j_{\delta_{i} \delta_{i}}}\right) \pi_{j_{c_{i}}}+\pi_{j_{\delta_{i}}}\left(\pi_{i_{c_{i} \delta_{i}}}+\beta \pi_{j_{c_{i} \delta_{i}}}\right)\right), \\
& \operatorname{sign}\left(\frac{d \delta_{i}}{d \beta}\right)=\operatorname{sign}\left(-\left(\pi_{i_{c_{i} c_{i}}}-K^{\prime \prime}+\beta \pi_{j_{c_{i} c_{i}}}\right) \pi_{j_{\delta_{i}}}+\pi_{j_{c_{i}}}\left(\pi_{i_{\delta_{i} c_{i}}}+\beta \pi_{j_{\delta_{i} c_{i}}}\right)\right) .
\end{aligned}
$$

The sign of the right-hand sides of both expressions is ambiguous if we do not make any further assumptions about the underlying demand functions. Obviously the slopes of the marginal $R \& D$ cost functions (together with the sign of the externalities) determine whether R\&D investment increases or decreases. Now, assume (i) negative externalities for process innovation due to absent or low technological spillovers such that $\pi_{j_{c_{i}}}>0$, and positive externalities for product innovation as in case of horizontal product differentiation, such that $\pi_{j_{\delta_{i}}}<0$. This implies decreased investment in process innovation, e.g. $c_{i_{\beta}}>0$, if the right-hand side of the first expression is positive, which is true in case:

$$
G^{\prime \prime}>\left(\pi_{i_{i} \delta_{i}}+\beta \pi_{j_{\delta_{i} \delta_{i}}}\right)-\left(\pi_{i_{c_{i} \delta_{i}}}+\beta \pi_{j_{c_{i} \delta_{i}}}\right) \frac{\pi_{j_{\delta_{i}}}}{\pi_{j_{c_{i}}}}:=\hat{G}^{\prime \prime} .
$$

A coordination of strategies increase investment in product innovation, e.g. $\delta_{i_{\beta}}<0$, whenever the right-hand side of the second expression is negative, or if:

$$
K^{\prime \prime}>\left(\pi_{i_{c_{i} c_{i}}}+\beta \pi_{j_{c_{i} c_{i}}}\right)-\left(\pi_{i_{\delta_{i} c_{i}}}+\beta \pi_{j_{\delta_{i} c_{i}}}\right) \frac{\pi_{j_{c i}}}{\pi_{j_{\delta_{i}}}}:=\hat{K}^{\prime \prime} .
$$

Alternatively, assume (ii) positive externalities for process innovation such that $\pi_{j_{c_{i}}}<$ 0 , e.g. due to strong technological spillovers, and negative externalities for product innovation as in case of mainly vertically differentiated products, such that $\pi_{j_{i}}>0$. 


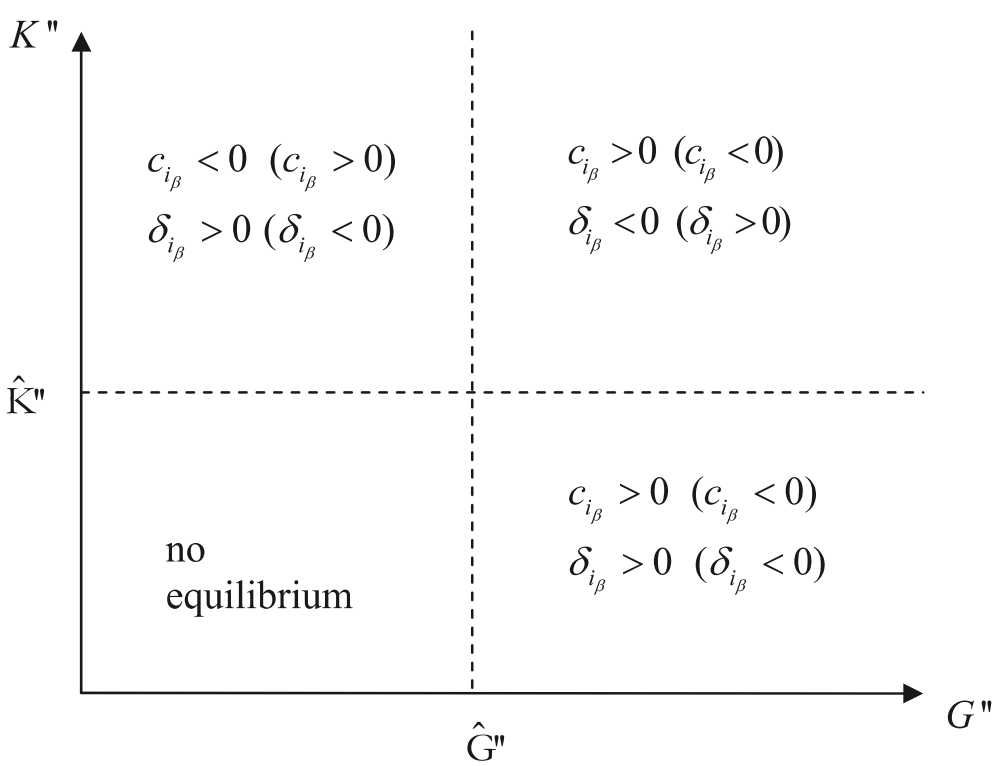

Fig. 1 Positive (negative) externalities for product innovation and negative (positive) externalities for process innovation

This would imply increased investment in process innovation, e.g. $c_{i_{\beta}}<0$, if $G^{\prime \prime}>\hat{G}^{\prime \prime}$ and decreased investment in product innovation, e.g. $\delta_{i_{\beta}}>0$, whenever $K^{\prime \prime}>\hat{K}^{\prime \prime}$.

Finally, assume (iii) positive (negative) externalities for process innovation and positive (negative) externalities for product innovation. This would imply increased (decreased) investment in both process and product innovation, if $G^{\prime \prime}>\hat{G}^{\prime \prime}$ and $K^{\prime \prime}>\hat{K}^{\prime \prime}$.

These conditions on the R\&D-cost functions can only be met if they allow for the existence of an equilibrium. To ensure that there exists an equilibrium for all values of $\beta$, the second-order condition has to be satisfied:

$$
G^{\prime \prime} \geq \pi_{i_{\delta_{i} \delta_{i}}}+\beta \pi_{j_{\delta_{i} \delta_{i}}}-\frac{\left(\pi_{i_{c_{i} \delta_{i}}}+\beta \pi_{j_{c_{i} \delta_{i}}}\right)^{2}}{\pi_{i_{c_{i} c_{i}}}+\beta \pi_{j_{c_{i} c_{i}}}-K^{\prime \prime}} .
$$

Substituting $\hat{K}^{\prime \prime}$ into this second-order condition of profit maximisation reveals that whenever $K^{\prime \prime}<\hat{K}^{\prime \prime}$ it is necessary for the equilibrium to exist that $G^{\prime \prime} \geq \hat{G}^{\prime \prime}$. Similarly, $G^{\prime \prime}<\hat{G}^{\prime \prime}$ requires that $K^{\prime \prime} \geq \hat{K}^{\prime \prime}$.

The above arguments for positive (negative) externalities for product innovation $\pi_{j_{\delta_{i}}}<0\left(\pi_{j_{\delta_{i}}}>0\right)$ and negative (positive) externalities for process innovation $\pi_{j_{c_{i}}}>0\left(\pi_{j_{c_{i}}}<0\right.$ ) are summarised in Fig. 1 (where $c_{i_{\beta}}<0$ implies increased investment into process innovation, $\delta_{i_{\beta}}<0$ implies decreased investment into product innovation). 


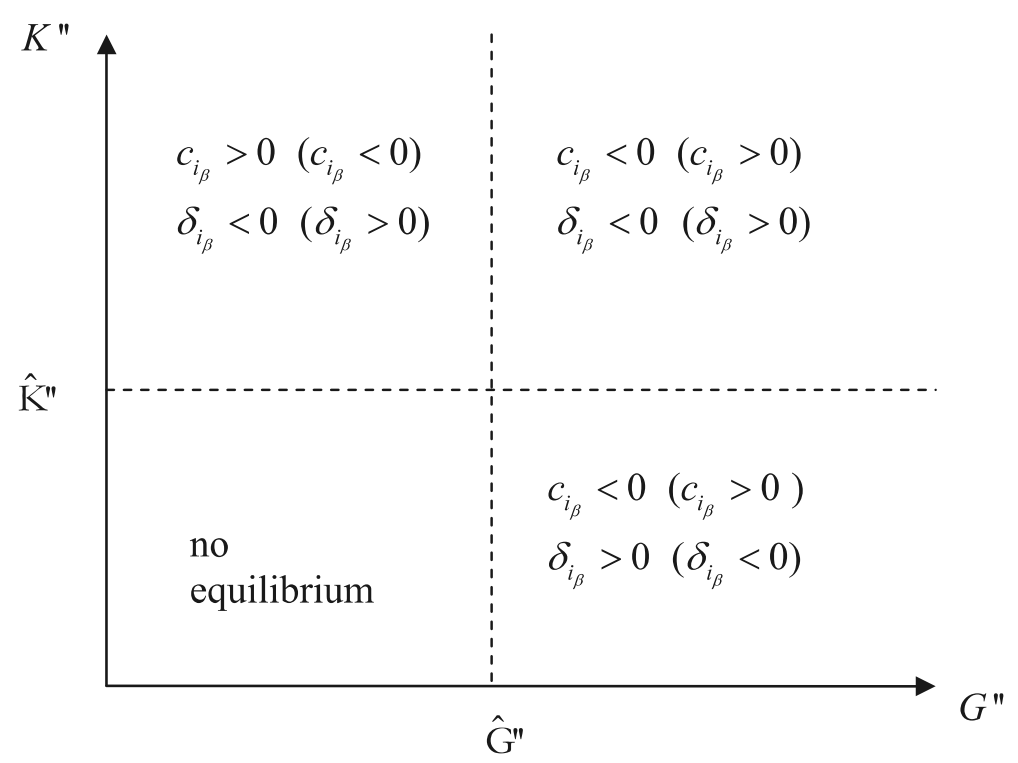

Fig. 2 Positive (negative) externalities for process as well as for product innovation

Figure 2 illustrates the situation if externalities for process innovation and for product innovation have the same positive (negative) sign:

It is obvious that only at the intersection of the two dotted lines investment would remain unchanged under coordinated decision making. These findings can be summarised in the following proposition:

Proposition 1 A coordination of strategies induces firms to change their $R \& D$ investment with regard to process innovation and to product innovation as compared to the independent situation whenever $K^{\prime \prime} \neq \hat{K}^{\prime \prime}$ and/or $G^{\prime \prime} \neq \hat{G}^{\prime \prime}$.

Proof See the arguments above.

Obviously we can expect to see unchanged R\&D strategies only under very specific assumptions on the R\&D cost functions. The more natural case will be that firms internalise the externalities from their investments by adjusting their R\&D investments. Furthermore, we can say something about the direction of the change if we make assumptions of the sign of the externalities, i.e. the level of technological spillovers and product market characteristics.

Proposition 2 Assume $K^{\prime \prime}>\hat{K}^{\prime \prime}$ and $G^{\prime \prime}>\hat{G}^{\prime \prime}$. A coordination of strategies induces firms

1. to invest more in product differentiation and less in process innovation if there are negative externalities for process innovation and positive externalities for product innovation;

2. to invest less in product differentiation and more in process innovation if there are positive externalities for process innovation and negative externalities for product innovation; 
3. to invest more in product differentiation and more in process innovation if there are positive externalities for both kinds of innovation;

4. to invest less in product differentiation and less in process innovation if there are negative externalities for both kinds of innovation.

Proof See the arguments above.

These findings correspond to the general economic insight, that the internalisation of positive externalities should increase incentives to conduct R\&D while the opposite should hold for negative externalities. ${ }^{14}$ We expect Case 1 in Proposition 2 to depict the most prominent situation as it suggests negative externalities and not too strong technological spillovers from process innovation and positive externalities from product innovation as in a predominantly horizontally differentiated market. For this case it can definitely be excluded that firms invest more in process innovation, $c_{i_{\beta}}<0$, and less into product differentiation, $\delta_{i_{\beta}}>0$, when they coordinate their research strategies (as compared to the competitive equilibrium). Keeping in mind that $\hat{K}^{\prime \prime}$ as well as $\hat{G}^{\prime \prime}$ are functions of R\&D spending one can simplify the interpretation for this case as follows: if both marginal R\&D-cost functions are sufficiently steep (such that $K^{\prime \prime}>\hat{K}^{\prime \prime}$ and $G^{\prime \prime}>\hat{G}^{\prime \prime}$ ), a coordination of strategies induce firms to invest more in product differentiation but less in process innovation. On the other hand, if marginal R\&D costs increase slowly for process innovation, that is $K^{\prime \prime}<\hat{K}^{\prime \prime}$, firms will invest less in both kinds of innovation compared to firms with independent R\&D. If marginal costs for process innovation are low, negative externalities become strong for competing firms and the internalisation of those strong negative externalities overcompensates positive externalities. If the slope of marginal $\mathrm{R} \& \mathrm{D}$ costs is low for product innovation, that is $G^{\prime \prime}<\hat{G}^{\prime \prime}$, firms invest more in both kinds of innovation. If firms can easily differentiate their products, the internalisation of positive externalities over-compensates negative externalities.

It is worthwhile to investigate whether firms also change the proportion of optimal $\mathrm{R} \& \mathrm{D}$ investment as compared to R\&D competition if they invest either more in both or less in both kinds of innovations. Consider the ratio of the first-order conditions of profit maximisation (1) and (2) given by:

$$
\frac{G^{\prime}}{K^{\prime}}=\frac{\pi_{i_{\delta_{i}}}+\beta \pi_{j_{\delta_{i}}}}{\pi_{i_{c_{i}}}+\beta \pi_{j_{c_{i}}}},
$$

and differentiate it with respect to $\beta$. Using (3) this yields:

$$
\begin{gathered}
\frac{\partial \frac{G^{\prime}}{K^{\prime}}}{\partial \beta}=\frac{G^{\prime \prime}\left(\pi_{i_{c_{i}}}+\beta \pi_{j_{c_{i}}}\right)-K^{\prime \prime}\left(\pi_{i_{\delta_{i}}}+\beta \pi_{j_{\delta_{i}}}\right)}{\left[G^{\prime}\left(\pi_{i_{c_{i}}}+\beta \pi_{j_{c_{i}}}\right)\right]^{2}}>0 \\
\Leftrightarrow K^{\prime \prime}\left(\pi_{i_{\delta_{i}}}+\beta \pi_{j_{\delta_{i}}}\right)<G^{\prime \prime}\left(\pi_{i_{c_{i}}}+\beta \pi_{j_{c_{i}}}\right)
\end{gathered}
$$

\footnotetext{
$\overline{14}$ See De Bondt and Veugelers (1991) for a comprehensive discussion of the effects of investment externalities.
} 
Table 1 Predictions of the effects of externalities on coordinated R\&D investments

\begin{tabular}{|c|c|c|c|c|c|c|c|}
\hline \multirow[t]{3}{*}{ Externalities } & \multirow[t]{3}{*}{ Type of innovation } & \multicolumn{6}{|c|}{ Coordinated $\mathrm{R} \& \mathrm{D}$ investment } \\
\hline & & \multicolumn{2}{|c|}{$\begin{array}{l}K^{\prime \prime}>\hat{K}^{\prime \prime} \\
G^{\prime \prime}>\hat{G}^{\prime \prime} \\
{[\text { Case } 1]}\end{array}$} & \multicolumn{2}{|c|}{$\begin{array}{l}G^{\prime \prime}<\hat{G}^{\prime \prime} \\
K^{\prime \prime} \geq \hat{K}^{\prime \prime} \\
{[\text { Case 2] }}\end{array}$} & \multicolumn{2}{|c|}{$\begin{array}{l}K^{\prime \prime}<\hat{K}^{\prime \prime} \\
G^{\prime \prime} \geq \hat{G}^{\prime \prime} \\
{[\text { Case 3] }}\end{array}$} \\
\hline & & Level & Ratio & Level & Ratio & Level & Ratio \\
\hline+ & Product & + & \pm & + & + & - & - \\
\hline+ & Process & + & & - & & + & \\
\hline+ & Product & + & + & + & + & - & - \\
\hline- & Process & - & & + & & - & \\
\hline- & Product & - & - & - & + & + & - \\
\hline+ & Process & + & & - & & + & \\
\hline- & Product & - & \pm & + & + & - & - \\
\hline- & Process & - & & - & & + & \\
\hline
\end{tabular}

Note that both sides are negative such that with positive externalities for product innovation and negative externalities for process innovation it is likely to observe that firms proportionately invest more into product innovation whenever $K^{\prime \prime} \geq \hat{K}^{\prime \prime}$. Considering the conditions on the marginal $\mathrm{R} \& \mathrm{D}$-cost functions, this ratio is most likely positive whenever firms invest more into both types of innovation. For the case that firms invest less into both kinds of innovation it is more likely that they shift their innovations towards more process innovation. On the other hand, for reversed externalities we expect to see a shift towards process innovation in case firms invest more into both kinds of innovation and a shift towards more product innovation in case firms invest less into both kinds of innovation. Table 1 summarises the results discussed above.

As Table 1 shows, the level and ratio of R\&D investments in coordinated strategies is expected to differ from independent strategies. As a starting point for the empirical testing of our model we can thus formulate the following three hypotheses:

Hypothesis 1 (product R\&D level): Coordinated strategies are associated with higher or lower levels of $R \& D$ investment with regard to product innovation when compared to independent strategies.

Hypothesis 2 (process R\&D level): Coordinated strategies are associated with higher or lower levels of $R \& D$ investment with regard to process innovation when compared to independent strategies.

Hypothesis 3 (product vs. process R\&D ratio): Coordinated strategies are associated with higher or lower ratios of product versus process $R \& D$ investments when compared to independent strategies.

Our model argues with externalities, but in principle, the expected changes in Hypotheses 1-3 can also be related to efficiency effects in coordinated R\&D strategies. Unfortunately, externalities per se are difficult to observe and measure. However, we 
have data on R\&D efficiency, which allows us to empirically test for the existence and direction of effects of efficiency. From this, together with the empirical results on the level and ratio of R\&D activities, we can then indirectly infer (by comparison with the predicted combinations of effects in Table 1), whether externalities may play a role at all (as proposed by our model), and if yes, which effect they might have.

Hypothesis 4 (product R\&D efficiency):

(a) Coordinated strategies are associated with higher $R \& D$ efficiency with regard to product innovation when compared to independent strategies.

(b) Coordinated strategies are associated with lower $R \& D$ efficiency with regard to product innovation when compared to independent strategies.

Hypothesis 5 (process R\&D efficiency):

(a) Coordinated strategies are associated with higher $R \& D$ efficiency with regard to process innovation when compared to independent strategies.

(b) Coordinated strategies are associated with lower $R \& D$ efficiency with regard to process innovation when compared to independent strategies.

If we observe that investment in both, product as well as process innovation, is increasing (decreasing) when firms coordinate their strategies, then this could alternatively be explained by an increase (decrease) in efficiency rather than the internalisation of externalities. On the other hand, if we observe an increase (decrease) in R\&D investment and at the same time a reduction (increase) in efficiency, this may indicate that externalities indeed play a role in determining coordinated R\&D decisions.

When we turn to the effect of coordination on aggregate R\&D the results of the formal model are more complex and do not exclude certain possibilities. In principle, if both types of innovations have the same sign of externalities and marginal R\&D-cost functions are equally steep (Case 1 in Table 1), we expect aggregate R\&D to decrease (increase) in case negative (positive) externalities are internalised. If extra investments do not strongly increase marginal R\&D-costs for only one type of innovation (Cases 2 and 3 in Table 1) and only this type has positive (negative) externalities, then the internalisation of the positive (negative) externalities can outweigh the opposite incentive from the other investment and aggregate $R \& D$ investment may increase (decrease). Moderately increasing marginal costs for both types of R\&D (Case 1 in Table 1) can lead to offsetting counter effects when externalities have opposite signs and thus to more or less unchanged aggregate investments. However, this is rather unlikely as the two opposing effects have to be equally strong. If there are strong differences in the R\&D-cost functions (Cases 2 and 3 in Table 1), the likelihood of exact compensation is even smaller. Hence, in correspondence to Hypotheses 3, we can formulate the following hypotheses on aggregate R\&D.

Hypothesis 6 (aggregate R\&D level): Coordinated strategies are associated with higher or lower levels of aggregate $R \& D$ investment with regard to process innovation and to product innovation when compared to independent strategies.

In correspondence to Hypotheses 4 and 5 we also test for possible differences between coordinated and independent strategies with regard to the existence and direction of aggregate efficiency effects, which may serve as an alternative explanation for changes in aggregate R\&D investment. 
Hypothesis 7 (aggregate R\&D efficiency): Coordinated strategies are associated with higher or lower aggregate $R \& D$ efficiency with regard to process innovation and to product innovation when compared to independent strategies.

\section{The data and the variables}

\subsection{The data}

Our empirical analysis uses data drawn upon two databases on Italian firms both developed by the Italian National Statistical Institute (ISTAT): the MICRO.1 database and the Italian CIS1 database.

The MICRO.1 database contains the result of an annual Industrial Census conducted in all industrial sectors during the period 1989-1997 on firms with 20 employees or more. Data on the Profit and Loss Account and the Balance Sheet are collected and organized along the normative guidelines of the IV Directive of the European Community Council. In this paper, the database is primarily used for total sales and employment data.

The Community Innovation Survey (CIS) is a comprehensive survey on innovation activities of firms covering European Union member States and European Union Candidate countries. The CIS has been designed to acquire information on various aspects of the innovation process that takes place inside firms, like the sources of information and knowledge, the different types of innovation, the effects of innovation on firm's performances, etc. The statistical unit is the enterprise, as defined in the Council Regulation ${ }^{15}$ or as defined in the statistical Business Register of the country. This regulation defines the enterprise as "the smallest combination of legal units that is an organisational unit producing goods or services, which benefits from a certain degree of autonomy in decision-making, especially for the allocation of its current resources", in other words, a company or a legally independent firm. ${ }^{16}$

CIS data are collected on a 4-year basis. As of 2007 four CIS surveys have been carried out: CIS1 referring to the 3-year period 1990-1992, CIS2 for 1994-1996, CIS3 for 1998-2000, and CIS4 for 2002-2004. The data requirements of our model are quite substantial and are not covered by all of the four surveys, or - to the best of our knowledge - by other large-scale and publicly available databases on innovative activities. In particular, we need data on the distinction between product and process innovations both for the input and output side. While all four Community Innovation Surveys collected product/process innovation data for the output side, only the first survey (CIS1) also made this distinction for innovation inputs. In particular, the first wave is the only one to report data on $R \& D$ expenses devoted to product innovations and $R \& D$ expenses devoted to process innovations. These data are necessary to test our hypotheses on efficiency in product or process innovations. Therefore, this paper focuses on the CIS1 in Italy.

\footnotetext{
15 Council Regulation (EEC) No. 696/93 of 15 March 1993, OJ No. L76 of the 3 March.

16 The aims, the methodology, the definitions and the questionnaire used in innovation surveys are described in the OECD Oslo Manual (OECD, 2nd edn, 1997; 3rd edn, 2005).
} 
The Italian CIS1 was carried out in 1994 by ISTAT on the innovative activities of firms in the manufacturing sector during the years 1990-1992. While the vintage of the data may limit the implications of some of our findings, the basic theoretical result and corresponding empirical claim of this paper focuses on showing the existence of externality effects in innovative activities, which is rather independent of the period studied. ${ }^{17}$

Although the CIS is professionally generated by several European National Statistical Offices and frequently used in diverse economic studies, we are aware of the fact that the first European CIS was less harmonised between European countries than subsequent surveys. The relatively high heterogeneity at country level gives rise to concerns about the quality of the data. Fortunately, in the case of Italy, the CIS1 data quality matches the standard of subsequent surveys. In fact, in some dimensions it even surpasses later surveys. For instance, while CIS2, CIS3 and CIS4 were sample surveys, based on stratified samples according to the industry classification (NACE) and firm size (number of employees), CIS1 was a census, which was sent to 33,268 manufacturing firms with more than 19 employees, of which 22,787 firms returned the questionnaire. ${ }^{18}$ The response rate of the Italian CIS1 was significantly higher (69\%), compared to the majority of subsequent waves in other European countries, which had response rates between 41 and 56\% (Eurostat 2003). Italian CIS1 data has been largely used in economic and statistical studies and to draw policy implications for enhancing innovativeness [see among others (Bartoloni and Baussola 2008, 2001; Crosato and Ganugi 2007; Evangelista et al. 2002; Sirilli and Evangelista 1998)].

While the CIS1 data on firms' innovative activities supply information on the period 1990-1992, some accounting variables (like total sales) only cover the year 1992. In order to be able to lag some of these variables we thus merge the CIS1 database with the MICRO.1 dataset described above. The merged sample consists of 18,467 firms across all manufacturing sectors for which, according to Scarpetta et al. (2004), firms with at least 20 employees represent more than $68 \%$ of the total employment in Italy. In a comparative analysis of innovative indicators (Kleinknecht 1996; Kleinknecht et al. 2002) show that the CIS indicators measure innovation input and output more comprehensively and more directly than earlier measures. Brouwer and Kleinknecht (1999) also find a systematic relationship between a firm's CIS innovation output and actual patenting data. Although the correlation is not perfect, this relationship holds for both the probability to apply for a patent as well as the actual number of patents. It is thus not surprising that CIS data have become a fundamental source to analyse innovation at the firm-level (among others, see Cassiman and Veugelers

\footnotetext{
17 Note that possible recent changes in R\&D efficiency, for example, due to rapid developments in information and communication technologies are not covered by the data. Such efficiency developments would not qualitatively change our results unless they affected independent and coordinated R\&D strategies in a structurally and significantly different manner. We thank one of the anonymous referees for pointing this out as it may provide an interesting extension to our model.

18 In the stratified samples of CIS2, CIS3 and CIS4, there are three size-classes: 20-49 employees (small) (in some countries, and depending on the wave, the first class starts at 10 employees), 50-249 employees (medium-sized), and more than 250 employees (large). The industrial stratification is by NACE at the 2-digit level. When a stratum size was too small for sampling (especially in countries with very few large firms) a census was done within the specific stratum.
} 
2002; Mairesse and Mohnen 2002, as recent contributions using CIS data). Despite these strong arguments for the CIS data, we readily acknowledge that innovation measurement is diverse and that the results in this paper are tied to the proxies at hand. As mentioned in the literature review, we are fully aware of an ongoing debate on the differences and similarities of various innovation measurements (see, e.g., Kleinknecht et al. 2002; Hagedoorn and Cloodt 2003).

The first Italian CIS is composed of ten questionnaire sections among which the first one requires general information of the firm and in particular whether the firm is member of a group. Whenever the answer is positive the firm is asked whether it is the group headquarters, and, in the negative case, whether the group headquarters is Italian or foreign.

Out of 18,467 firms 3302 respondents (17.9\%) declared themselves member of a group. We consider these respondents not to be completely independent in their innovation strategies and label them GROUP. In fact, the claim to be a group member can be interpreted as the willingness to (at least partially) coordinate innovation strategies and decisions within organizational structures of shared decision control. In principle, this claim allows various vehicles for coordination, including joint ventures, acquisitions, alliances or any form of joint decision making. Based on the context of the specific questionnaire item, however, we conservatively assume that the claim to be 'part of a group' primarily refers to equity-related organizational attachments, like acquisitions or equity joint ventures. ${ }^{19}$

Such an equity-based definition comes with two caveats: First, it excludes nonequity forms of coordination, like contractual alliances or informal collaborations. This opens the possibility that some independent firms may coordinate their innovative activities with external (non-equity) partners to the same or even a larger extent than group members. However, for testing our hypotheses, the important question is whether firms within an equity-based group are-on average — subject to greater coordination (within the group's overall product market policy) than independent firms. On the basis of a similar research question, Villalonga and McGahan (2005) analyse 9,276 acquisitions, alliances and divestitures during the 1990s. In support of our proxy, they show that firms prefer acquisitions over alliances when they intent to appropriate and coordinate intangible resources from the focal firm. Further, Allen and Phillips (2000) show that this even applies to the corporate acquisition of minority equity blocks. In their study the primary reason for corporate equity ownership (with an average of $20 \%$ of voting shares) are benefits in the product market optimization and coordination, particularly in industries with high research and development. ${ }^{20}$ Further, using the same data that we use in this paper, Evangelista et al. (2002) study regional systems of innovations, defined as a 'localised network of actors and institutions [...] whose activities and interactions generate, import, modify and diffuse new technologies' (Evangelista et al. 2002, p. 174). Their answer to the question, whether they can

\footnotetext{
19 The specific question asked in Sect. 1 of the questionnaire is: 'Is your firm part of a group? This question is followed by the following item, which can be interpreted as an equity-related definition of the term group: 'If you are part of a group, is your firm the group headquarters?'

20 They also provide evidence that increases in operating performance and investments are strongest in cases when alliances and joint ventures are combined with corporate ownership in high R\&D industries.
} 
identify such networks in Italy 'is clearly negative, at least for most of the regional clusters identified by our empirical analysis' (Evangelista et al. 2002, p. 184).

A second potential caveat of an equity-based definition of groups is the fact that group membership as such does not guarantee the coordination of innovative activities. In fact, individual or institutional financial investors may buy and sell substantial (even controlling) stakes in subsidiaries purely for portfolio reasons. In contrast to corporate investors, portfolio investors do not coordinate managerial activities between the assets in their portfolio. However, studies from Filatotchev et al. (2003) and Piga and Vivarelli (2004), show that headquarters are very active innovators within groups. These results stand in stark contrast to the notion of portfolio investment of purely financial holdings. This support for our proxy is particularly relevant, because both studies use data from the Italian manufacturing industry (as we do in this paper). Taken together, the above evidence provides support that firms' claim 'to be part of a group', even when defined conservatively as equity-based membership, can be interpreted as a proxy for, on average, a higher level of coordination, compared to the rest of the firms in the sample.

Altogether, 15,165 respondents $(82.1 \%)$ did not see themselves as part of any group. We assume that these are, on average, independently competing firms and label them INDEP. Table 2 describes the complete sample and the two sub-samples in more detail.

Not surprisingly, the average size of companies in GROUP and INDEP is noticeably different with regard to most moments. Firms belonging to groups (GROUP) have average total sales that are almost 9.5 times larger than those of independent firms (INDEP) and the median is 4 times larger. Furthermore the mean of the number of employees in GROUP is 6 times larger and the median almost 3 times. In general, we can observe that the entire distributions of firms belonging to groups are shifted upward with respect to those of independent firms, regardless the proxy for size: total sales or number of employees.

Since the theoretical model gives predictions on the proportion between product and process $R \& D$ expenses, firms with positive $R \& D$ expenses are our target population. Therefore, we select all firms with a positive R\&D budget. Table 3 describes this sub sample of 3,696 firms, split up into GROUP (coordinated R\&D strategies) and INDEP (independent R\&D strategies). It is worth noting that the magnitude of the size difference in Table 2 persists in the sub sample of firms investing in R\&D: in Table 3

Table 2 Descriptive statistics of Italian manufacturing firms in 1st CIS, 1992

\begin{tabular}{|c|c|c|c|c|c|c|}
\hline & \multicolumn{2}{|l|}{ Total sample } & \multicolumn{2}{|l|}{ GROUP } & \multicolumn{2}{|l|}{ INDEP } \\
\hline & $\begin{array}{l}\text { Total sales } \\
\text { (in '000 €) }\end{array}$ & Employees & $\begin{array}{l}\text { Total sales } \\
\text { (in '000 €) }\end{array}$ & Employees & $\begin{array}{l}\text { Total sales } \\
\text { (in '000 } € \text { ) }\end{array}$ & Employees \\
\hline$N$ & 18,467 & 18,467 & 3,302 & 3,302 & 15,165 & 15,165 \\
\hline Mean & 14,990 & 104 & 56,205 & 326 & 6,016 & 55 \\
\hline SD & 189,241 & 859 & 443,305 & 1,998 & 19,497 & 128 \\
\hline 25th petl & 1,728 & 27 & 4,835 & 43 & 1,538 & 26 \\
\hline Median & 3,477 & 37 & 11,728 & 94 & 2,887 & 34 \\
\hline 75th pctl & 8,112 & 71 & 30,978 & 230 & 5,912 & 55 \\
\hline
\end{tabular}


Table 3 Descriptive Statistics of Italian manufacturing firms with a positive R\&D budget, 1992

\begin{tabular}{lcllll}
\hline & GROUP & & & INDEP \\
\cline { 2 - 3 } \cline { 6 - 6 } & Total sales (in '000 $€$ ) & Employees & & Total sales (in '000 $€$ ) & Employees \\
\hline$N$ & 1,266 & 1,266 & & 2,430 & 2,430 \\
Mean & 110,205 & 606.06 & & 9,846 & 87.34 \\
SD & 709,821 & 3176.12 & & 18,841 & 284.34 \\
25th pctl & 8,078 & 72 & & 2,633 & 30.00 \\
Median & 21,272 & 168.00 & & 5,019 & 46.50 \\
75th pctl & 56,640 & 435 & & 10,329 & 88 \\
\hline
\end{tabular}

the median (mean) of sales of all firms in GROUP is about 4.2 (11.2) times larger than the corresponding size in INDEP. Again, as for the total CIS sample, the entire distributions of firms belonging to groups are shifted upwards, regardless the proxy for size.

\subsection{The variables}

Sections 6 and 8 of the first Italian CIS focus respectively on R\&D activities and on the effects on firm's performance of innovation activities. Data pertaining to these sections provide detailed measures of innovation inputs and outputs, which we use as such or partially transform. Our empirical investigation focuses on investment, performance and efficiency variables, which are defined in subsection (i). Subsection (ii) specifies the independent variables of interest and some additional control variables. All variable names are in capital letters:

(i) Dependent Variables ${ }^{21}$

Investment variables (input-related):

TOT-IN:

PROD-IN:

PROC-IN :

PROD-REL-IN:

PROC-REL-IN: total R\&D expenses divided by total sales

$\mathrm{R} \& \mathrm{D}$ expenses devoted to product innovation divided by total sales

$\mathrm{R} \& \mathrm{D}$ expenses devoted to process innovation divided by total sales (PROD-IN and PROC-IN complement to $100 \%$ of total R\&D expenses)

$R \& D$ expenses in product innovation as percentage of total R\&D expenses

$R \& D$ expenses in process innovation as percentage of total R\&D expenses

\footnotetext{
21 Reference year is 1992 unless otherwise mentioned.
} 


\section{Performance variables (output-related):}

TOT-OUT:

PROD-OUT:

PROC-OUT:

Efficiency variables:

TOT-EFF:

PROD-EFF:

PROC-EFF: percentage of total sales realised with new products and processes

percentage of total sales realised with new products percentage of total sales realised with new processes
TOT-OUT/TOT-IN ${ }_{t-1}$ (with TOT-IN $\mathrm{w}_{t-1}=$ TOT-IN lagged by 1 year)

PROD-OUT/PROD-IN ${ }_{t-1}$ (with PROC-IN $t_{t-1}=$ PROC-

IN lagged by 1 year)

PROC-OUT/PROC-IN ${ }_{t-1}$ (with PROC-IN ${ }_{t-1}=$ PROCIN lagged by 1 year)

Coordination variable:

GROUP:

Dummy variable indicating whether a firm belongs to a group

(ii) Independent Variables

GROUP_PROB: Predicted probability that a firm belongs to a group

SIZE:

Log of total sales in 1992 (in '000 Euro)

SIZE_EMP 1990 : $\quad$ Log of total employees in 1990

HQ_DUM: Dummy variable indicating whether a group is headquartered outside Italy

AT15; ..., AT36: $\quad$ Industry dummies at 2-digit SIC level (from 15 to 36)

SCIENCE_BASED; In order to control for differences in the nature of technoSUPPLIER_DOM; logy, the source and the appropriation of innovations and SPEC_SUPPL; their influence on product and process innovations, we SCALE_INTENSIVE: classify our firms according to Pavitt's taxonomy (Pavitt 1984). As a result, we have four dummies, one for each of the Pavitt's categories of firms: science-based, supplier dominated, specialised suppliers, and scale intensive. ${ }^{22}$

\section{Empirical results}

\subsection{Non-parametric analysis}

We initially perform a non-parametric analysis in order to test our hypotheses. Table 4 reports the descriptive statistics of the variables of interest, while Table 5 shows the corresponding results of different two-sample tests, namely Levine' ${ }^{23}$ test for the equality

\footnotetext{
22 See the literature review of this paper for a more elaborate explanation of the Pavitt's taxonomy and the 4 dummies that we have derived from it.

${ }^{23}$ We perform the Levine's test for the equality of variance among the two sample distributions. According to the Levine's test results, we apply a Student's $t$ test to check whether the means of the two sample distributions (with equal or not equal variance) are statistically different. We use a pooled- or separatevariances $t$ test for equality of means according to the results of Levine's test for the equality of variances.
} 
Table 4 Descriptive statistics

\begin{tabular}{|c|c|c|c|c|c|c|c|c|}
\hline Variable & Sample & $N$ & Mean & Median & Variance & $\begin{array}{l}\text { Coef. } \\
\text { of Var. }\end{array}$ & Skewness & Kurtosis \\
\hline \multirow[t]{2}{*}{ TOT-IN } & Group & 1,266 & 0.0326 & 0.014 & 0.004 & 198.002 & 7.960 & 90.160 \\
\hline & Independent & 2,430 & 0.029 & 0.014 & 0.002 & 174.364 & 6.258 & 56.350 \\
\hline \multirow[t]{2}{*}{ PROD-IN } & Group & 1,266 & 0.023 & 0.009 & 0.003 & 216.501 & 8.024 & 97.436 \\
\hline & Independent & 2,430 & 0.018 & 0.008 & 0.001 & 191.025 & 7.390 & 89.317 \\
\hline \multirow[t]{2}{*}{ PROC-IN } & Group & 1,266 & 0.009 & 0.003 & 0.001 & 263.384 & 10.042 & 138.695 \\
\hline & Independent & 2,430 & 0.011 & 0.003 & 0.001 & 272.678 & 8.416 & 93.2882 \\
\hline \multirow[t]{2}{*}{ PROD-REL-IN* } & Group & 1,266 & 64.526 & 70 & 976.387 & 48.426 & -0.657 & -0.686 \\
\hline & Independent & 2,430 & 61.647 & 70 & 1055.748 & 52.707 & -0.502 & -0.881 \\
\hline \multirow[t]{2}{*}{ PROC-REL-IN* } & Group & 1,266 & 35.474 & 30 & 976.387 & 88.085 & 0.657 & -0.686 \\
\hline & Independent & 2,430 & 38.353 & 30 & 1055.748 & 84.7188 & 0.502 & -0.881 \\
\hline \multirow[t]{2}{*}{ TOT-OUT } & Group & 1,266 & 55.043 & 60 & 1063.610 & 59.250 & -0.145 & -1.260 \\
\hline & Independent & 2,430 & 57.782 & 60 & 944.593 & 53.190 & -0.283 & -1.062 \\
\hline \multirow[t]{2}{*}{ PROD-OUT } & Group & 1,266 & 33.937 & 30 & 839.645 & 85.384 & 0.697 & -0.463 \\
\hline & Independent & 2,430 & 35.040 & 30 & 776.875 & 79.544 & 0.593 & -0.490 \\
\hline \multirow[t]{2}{*}{ PROC-OUT } & Group & 1,266 & 21.107 & 10 & 671.052 & 122.732 & 1.598 & 2.012 \\
\hline & Independent & 2,430 & 22.742 & 15 & 675.344 & 114.273 & 1.460 & 1.656 \\
\hline \multirow[t]{2}{*}{ TOT-EFF } & Group & 1,266 & 113.552 & 29.323 & 176841.549 & 370.336 & 11.812 & 177.193 \\
\hline & Independent & 2,430 & 86.567 & 33.301 & 30413.887 & 201.458 & 6.256 & 61.919 \\
\hline \multirow[t]{2}{*}{ PROD-EFF } & Group & 1,177 & 109.919 & 23.848 & 229341.875 & 435.681 & 14.397 & 273.117 \\
\hline & Independent & 2,192 & 90.348 & 27.624 & 143475.731 & 419.247 & 31.581 & 1260.148 \\
\hline \multirow[t]{2}{*}{ PROC-EFF } & Group & 1003 & 160.508 & 42.654 & 209902.759 & 285.438 & 8.517 & 101.190 \\
\hline & Independent & 1,894 & 157.129 & 43.766 & 232239.664 & 306.700 & 15.368 & 368.338 \\
\hline
\end{tabular}

* The variables complement to 100, therefore, as expected, the distributions of GROUP and INDEP firms have complementary means, same variance, opposite Skewness, and same Kurtosis

of variance, the Student's $t$ test for the equality of the means and the KolmogorovSmirnov $^{24}$ test for the equality of the location and the shape of the entire empirical distributions.

As predicted by our model (Hypotheses 1 and 2), Table 4 reports that firms within and without a group invest at different levels into product and process R\&D (PRODIN, PROC-IN). In fact, independent firms spent, on average, $21.7 \%$ less (22.2\% more) on product (process) R\&D than firms with coordinated strategies. In total, independent firms invest $11.0 \%$ less in aggregate R\&D (TOT-IN) than firms that are part of a group ( $2.9 \%$ vs. $3.26 \%$ of sales). However, as we can see from the two-sample tests in Table 5, only the differences in the level of product $R \& D$ and in aggregate $R \& D$ are significant,

\footnotetext{
24 The Kolmogorov-Smirnov test is a non-parametric test for the null hypothesis that a random sample has been drawn from a specified theoretical (discrete or continuous) distribution. The test is also used, as in our case, to examine whether two samples come from the same distribution. It is sensitive to any type of difference in the two distributions-shape, location, etc. The test is based on the largest difference between the two cumulative distributions.
} 
Table 5 Two-sample tests for GROUP and INDEP firms

\begin{tabular}{|c|c|c|c|c|c|c|}
\hline & \multicolumn{2}{|c|}{ Levene's test } & \multicolumn{2}{|c|}{ Student's $t$ test ${ }^{\mathrm{a}}$} & \multicolumn{2}{|c|}{ Kolmogorov-Smirnov test } \\
\hline & $F$ & $p$ value & $T$ & $p$ value & $Z$ & $p$ value \\
\hline TOT-IN & $10.481^{* * *}$ & 0.001 & $-1.936^{*}$ & 0.053 & $1.310^{*}$ & 0.065 \\
\hline PROD-IN & $33.796^{* * *}$ & 0.000 & $-3.403^{* * *}$ & 0.001 & $1.492^{* *}$ & 0.023 \\
\hline PROC-IN & $4.610^{* *}$ & 0.032 & 1.445 & 0.149 & 0.563 & 0.909 \\
\hline PROD-REL-IN & $4.849^{* *}$ & 0.280 & $-2.622^{* * *}$ & 0.009 & $1.919^{* * *}$ & 0.001 \\
\hline PROC-REL-IN & $4.849^{* *}$ & 0.280 & $2.622^{* * *}$ & 0.009 & $1.919^{* * *}$ & 0.001 \\
\hline TOT-OUT & $15.701^{* * *}$ & 0.000 & $2.470^{* *}$ & 0.014 & $1.776^{* * *}$ & 0.004 \\
\hline PROD-OUT & $3.101^{* *}$ & 0.078 & 1.127 & 0.260 & $1.391^{* *}$ & 0.042 \\
\hline PROC-OUT & 0.297 & 0.585 & $1.817 *$ & 0.069 & $1.905^{* * *}$ & 0.001 \\
\hline TOT-EFF & $28.400^{* * *}$ & 0.000 & $-2.187^{* *}$ & 0.029 & $1.589^{* *}$ & 0.013 \\
\hline PROD-EFF & $6.602^{* * *}$ & 0.010 & -1.213 & 0.225 & $1.308 *$ & 0.065 \\
\hline PROC-EFF & 0.223 & 0.637 & -0.186 & 0.853 & 0.492 & 0.969 \\
\hline
\end{tabular}

$*, * *, * * *$ Statistical significance at the $0.1,0.05$, and 0.01 level, respectively

a The statistics reported in the table are calculated using pooled- or separate-variances $t$ tests for equality of means according to the results of Levine's test for the equality of variances

which supports Hypotheses 1 and 6, but not Hypothesis 2. The significantly different investment levels in product $R \& D$ are also reflected in the product versus process $\mathrm{R} \& \mathrm{D}$ ratio.

Table 4 reports that firms that are part of a group invest, on average, a $4.7 \%$ higher (lower) share of their total R\&D budget in new products (processes) than independent firms. The corresponding two-sample tests in Table 5 show that the means of PRODREL-IN (PROC-REL-IN) are statistically different (at the 1\% level) between GROUP and INDEP, as are the entire distributions of the two samples. The non-parametric analysis thus also supports Hypothesis 3 .

In principle, some of the above findings can be a result of an improved efficiency in coordinated strategies. If $R \& D$ is more efficient in groups, member firms may have an incentive to invest more in product and/or process innovation. In contrast to this, Table 4 reports that the mean efficiency of firms in a group is lower for product, process, as well as aggregate $\mathrm{R} \& \mathrm{D}$. With regard to product and of process R\&D, Table 5 reports that the differences between the means are statistically not significant. Also, the differences between the distributions of the two samples differ only moderately with regard to product R\&D (PROD-EFF) at the $10 \%$ level. With regard to aggregate $\mathrm{R} \& \mathrm{D}$, Table 5 reports that the lower efficiency of firms that belong to a group is statistically significant, both, in the Student's $t$ test and in the Kolmogorov-Smirnov test (at the 5\% level). Together these results neither support Hypothesis 5, nor fully support Hypothesis 4 (b), indicating little efficiency effects in product or process R\&D. Although we find some statistically significant differences, as predicted by Hypothesis 7, they report a lower aggregate R\&D efficiency in coordinated strategies. As our model predicts, the empirical results therefore point towards the existence of other effects, like externalities, which may explain the higher levels of (product and aggregate) R\&D investment in groups. 


\subsection{Multivariate analysis}

The aim of this section is to check whether the previous results on the relationships between being part of the group and the innovation proxies are robust when other independent factors (like size and having a foreign headquarters) are held constant. In order to analyse the correlations specified in our hypotheses, we firstly acknowledge that being part of a group could depend on the firm size and on the industrial sector in which the firm carries out its principal activity. Firm size and sector characteristics could in turn affect the innovative input, output and efficiency, giving rise to an endogeneity problem. To tackle this issue, we estimate a logit model in which the probability of being part of the group depends on the size of the firms and on the industrial sector at 2 digit-level. As size variable we include the logarithm of the number of employees in the year 1990 (SIZE_EMP). We lagged this variable to minimise endogeneity and to justify the inclusion of this variable as an ex-ante explaining variable. Table 6 shows that the probability of a firm to belong to a group significantly depends on its size and on the industrial sector in which it operates. Indeed, the coefficients of the firm size and many of firms' industrial sector dummies are statistically significant at 5\% level.

Given these results, we use the predicted probabilities estimated by the logit model as the independent variable of interest in the subsequent linear regressions. Table 4 shows the variables that we use as dependent variables. Further, we also include a number of additional control variables.

In Rosenkranz (2003), market size exerts an important influence on the R\&D portfolio, by increasing (decreasing) the relative incentives to invest in product (process) R\&D. Since the model directly relates market size to firm size, we include the latter to control for this effect. In order to better differentiate the multivariate regression from the logit estimation, we use the log of firm total sales in 1992. Local subsidiaries of foreign parent firms may be subject to global specialization in R\&D, including outsourcing activities and a possible extraction of product and/or process R\&D to other countries. We therefore include a dummy, which equals 1 if the headquarter of the group is outside of Italy, 0 otherwise. Furthermore, we apply Pavitt's (1984) taxonomy to our firms in order to broadly control for the nature of the technology and the industrial characteristics. Pavitt (1984) identifies four different categories of firms based on the interaction of several market, technology and innovation characteristics. As explained in the literature review, this taxonomy identifies supplier dominated firms, specialised suppliers firms, scale intensive firms and science based firms and relates them to product and process innovations. According to Pavitt's (1984) taxonomy, we have introduced three dummies (we have dropped the category scale intensive) that take value 1 when firms belong to that category and 0 otherwise.

Tables 7 and 8 report the results of the linear regressions where the independent variable of interest is GROUP_PROB, the predicted probabilities of firms to belong to a group. Given the heteroskedasticity, we implement the Huber (1967) and White (1980) sandwich estimator of variance.

Table 7 reports the results of the regressions on R\&D investment levels and ratios, which serve as tests for Hypotheses 1-3 and Hypothesis 6. Corroborating the nonparametric results, Hypotheses 1 and 6 are supported again since coordinated R\&D strategies are, on average, related to significantly different (higher) levels of product 
Table 6 Logistic regression (ML) of the probability to belong to a "group" in 1992

\begin{tabular}{lrlll}
\hline Dependent: GROUP & Coeff. & Std. Err. & $z$ & $P>|z|$ \\
\hline SIZE_EMP 1990 & 1.15 & 0.05 & 25.30 & 0.000 \\
AT15 & -1.46 & 0.59 & -2.48 & 0.013 \\
AT17 & -1.44 & 0.58 & -2.49 & 0.013 \\
AT18 & -2.05 & 0.67 & -3.07 & 0.002 \\
AT19 & -1.98 & 0.65 & -3.05 & 0.002 \\
AT20 & -1.67 & 0.66 & -2.52 & 0.012 \\
AT21 & -0.97 & 0.63 & -1.53 & 0.126 \\
AT22 & -1.00 & 0.66 & -1.51 & 0.130 \\
AT23 & 0.09 & 0.78 & 0.11 & 0.913 \\
AT24 & -0.61 & 0.57 & -1.06 & 0.287 \\
AT25 & -1.08 & 0.58 & -1.86 & 0.062 \\
AT26 & -1.07 & 0.58 & -1.85 & 0.064 \\
AT27 & -1.26 & 0.60 & -2.09 & 0.037 \\
AT28 & -1.33 & 0.57 & -2.33 & 0.020 \\
AT29 & -1.22 & 0.56 & -2.17 & 0.030 \\
AT31 & -1.16 & 0.58 & -2.01 & 0.044 \\
AT32 & -0.80 & 0.60 & -1.32 & 0.186 \\
AT33 & -1.20 & 0.59 & -2.03 & 0.043 \\
AT34 & -1.31 & 0.60 & -2.19 & 0.028 \\
AT35 & -1.54 & 0.64 & -2.41 & 0.016 \\
AT36 & -1.80 & 0.59 & -3.04 & 0.002 \\
_cons & -4.65 & 0.58 & -7.97 & 0.000 \\
N & 3696.00 & & & \\
LR $\chi^{2}(21)$ & 1101.22 & $P>\left(\chi^{2}\right)$ & 0.000 & \\
Pseudo- $R^{2}$ & 0.23 & & & \\
\hline & & & & \\
& & & & \\
& & & & \\
& & & & \\
\end{tabular}

and aggregate $R \& D$. In contrast to the non-parametric tests, the significant coefficient of GROUP_PROB on PROC-IN corroborates Hypothesis 2, which predicts different process R\&D levels. As independent firms are much smaller than firms in a group (see Table 3), controlling for firm size corrects for the generally higher level of investment (as percentage of sales) of smaller firms into R\&D. This can be seen in Table 7, where the control variable SIZE has a significantly negative coefficient when regressed on the level of product, process, and aggregate $R \& D$, measured as a percentage of sales (PROD-IN, PROC-IN, TOT-IN, respectively).

Firm size may also explain why, in contrast to the non-parametric case, Hypothesis 3 is not supported anymore. In fact, the coefficients of GROUP_PROB are not significant when regressed on PROD-REL-IN or PROC-REL-IN, indicating that the difference in $\mathrm{R} \& \mathrm{D}$ portfolios (ratio of product vs. process $\mathrm{R} \& \mathrm{D}$ ) is mainly associated with firm size. This is principally in line with Rosenkranz (2003), who shows theoretically that firm size is positively associated with the relative importance of product $R \& D$ in the total 


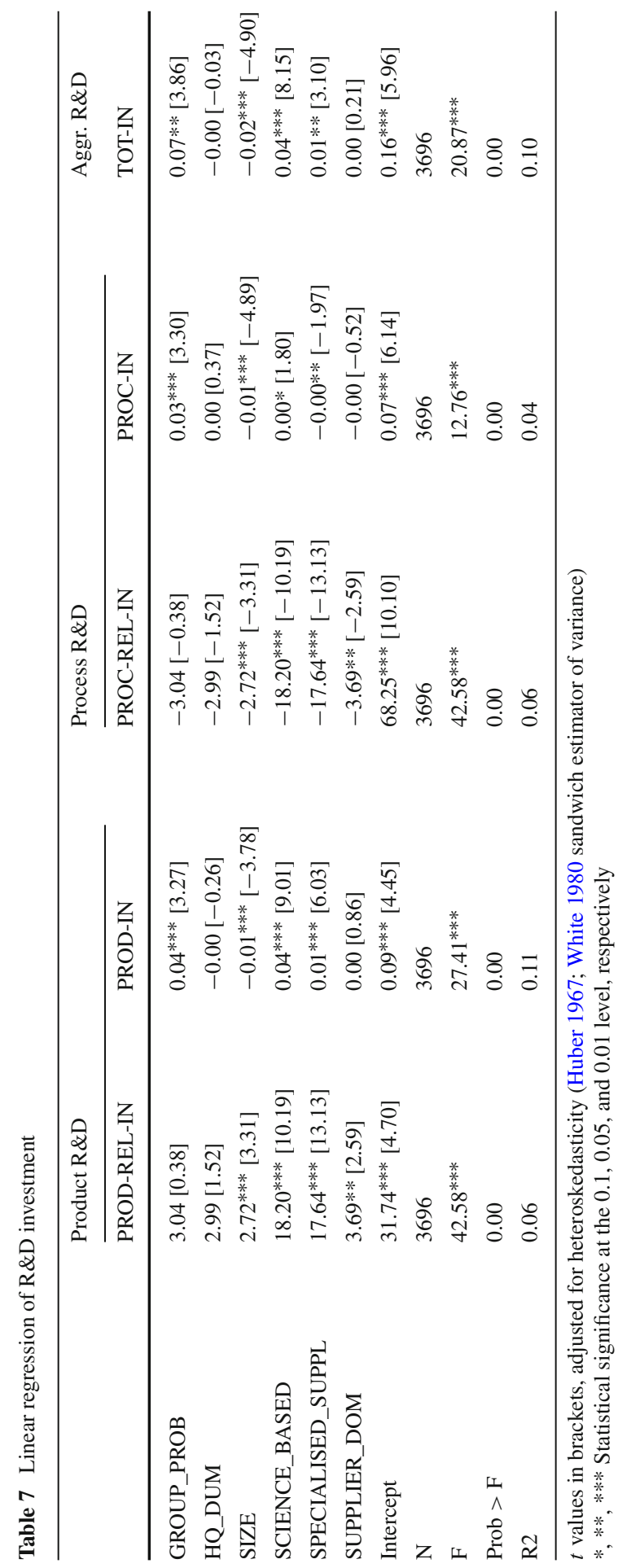




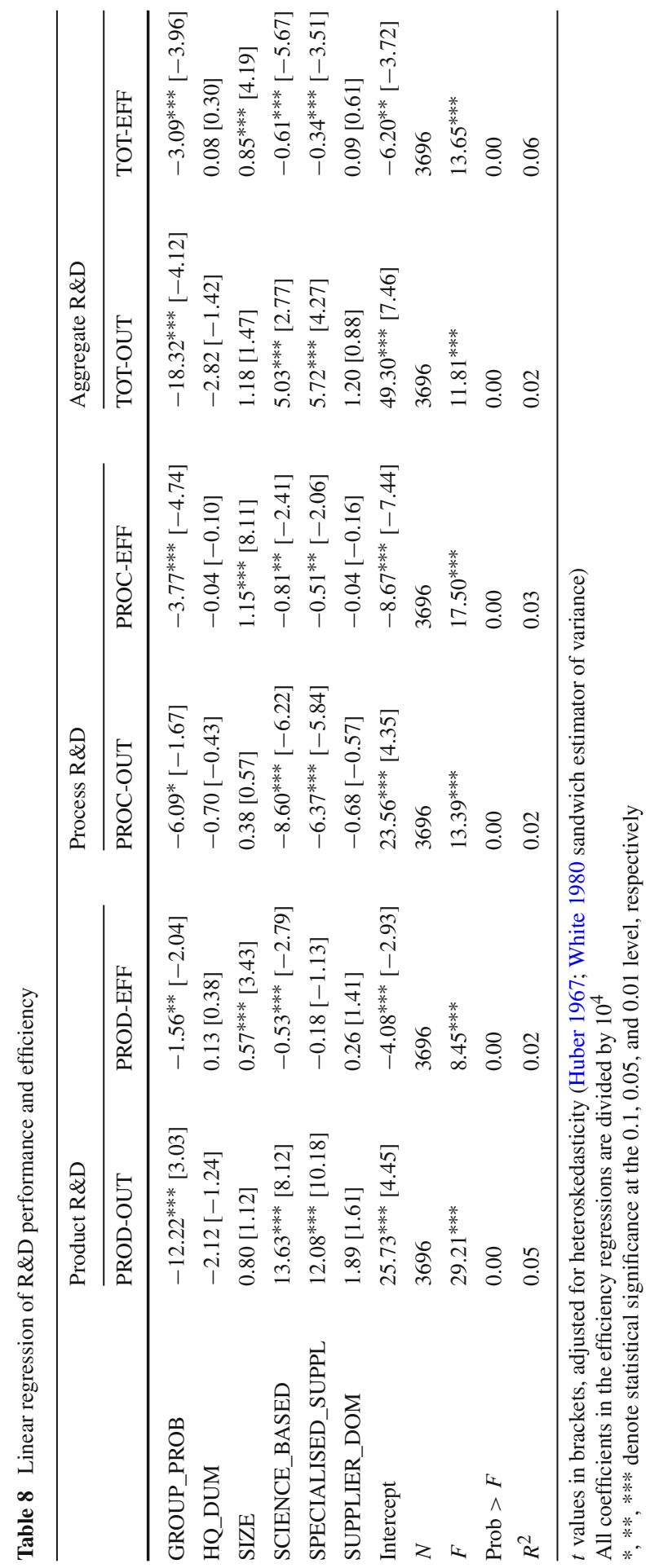


portfolio. Accordingly, the coefficient of the control variable SIZE is also positively (negatively) statistically significant when regressed on PROD-REL-IN (PROC-RELIN). It is also interesting to note that, when examining the control variables, the fact that having the groups' headquarters located outside Italy does not seem to statistically relate to differences in $\mathrm{R} \& \mathrm{D}$ investment levels or portfolios between coordinated or independent R\&D strategies. ${ }^{25}$

Table 8 reports the results of the regressions on R\&D performance and efficiency, which serve as tests for Hypotheses 4, 5, and 7. Before we turn to the analysis of R\&D efficiency we first take a brief look at the influence of the probability of coordinated strategies (GROUP_PROB) on R\&D performance or output (see PROD-OUT, PROCOUT, and TOT-OUT in Table 8). Interestingly, the tendency of firms with coordinated strategies to invest more in $R \& D$, which we observe in Table 7, is associated with a lower output of product, process, and aggregate R\&D. We find that the respective coefficients of GROUP_PROB in Table 8 are negative and statistically significant. Consequently, the probability of being part of a group is also negatively related to the efficiency of product, process, and aggregate $R \& D$, as the statistically significant coefficients of GROUP_PROB show. In the multivariate analysis we can therefore support Hypotheses 4(b), 5(b), as well as Hypothesis 7. Again, as argued in connection with the non-parametric tests, we interpret the negative R\&D efficiency of coordinated strategies as a strong indication that other effects, like externalities, explain the higher R\&D investment levels, as shown in the tests of Hypotheses 1 and 2.

\section{Concluding remarks}

The purpose of this paper is twofold. As a contribution to theory building, this paper proposes a generalized model where market externalities explain differences in firms' propensity to invest in product and process R\&D. Specifically, our model predicts that the coordination of strategies induces firms to internalise strategic effects of product and process innovations, which lead to different levels of R\&D investment than independent decisions. Taking into consideration that process and product R\&D may exercise different externalities, our model predicts specific relations between the signs of the externalities and the direction of change of relative R\&D investment. The empirical results largely support our theoretical predictions.

A second contribution of this paper are the implications for management and policy makers that can be derived from the empirical analysis of our model. ${ }^{26}$ With regard to managerial implications the empirical findings provide a better understanding of how market externalities affect a firm's approach to innovation. In line with Filatotchev et al. (2003) we find that firms that belong to a group invest significantly more into aggregate R\&D than independent firms. Our results show that this applies both to product as well as process R\&D. Despite higher absolute investment in both types of

\footnotetext{
25 This result is also supported by unreported robustness checks with samples that exclude all firms that report to be part of a group with foreign headquarters.

26 Particularly for the implications, please note the data limitations discussed in connection with the data description.
} 
innovation, a bivariate analysis indicates that the $R \& D$ portfolio of firms that belong to a group is more intensive in product $R \& D$. In a multivariate setting this result is attributed to firm size. The most important implication for managerial decision making probably is that these results are not driven by efficiency gains for firms in a group. In fact, despite higher total $R \& D$ investment, firms in a group have a lower R\&D efficiency than independently competing firms, particularly in process R\&D. On the basis of our model this implies that a firm's intensity in product, process and aggregate R\&D crucially depends on the externalities of these two types of innovative activities and on the firm's ability to internalize them.

With regard to policy implications, the empirical results enable us to identify the type of externalities of product and process R\&D in the Italian manufacturing industry, which can serve as a basis for more specific recommendations. Referring back to Table 1, the multivariate results position our Italian sample in the first row and first column. Based on the assumptions underlying our theoretical model, the empirical results thus indicate that coordinated decisions on $R \& D$ portfolios are affected by the internalisation of positive externalities, both in product $\mathrm{R} \& \mathrm{D}$ and in process $\mathrm{R} \& \mathrm{D}$.

Positive externalities in product $\mathrm{R} \& \mathrm{D}$ point towards a relatively low substitutability of Italian product innovations, indicating $\mathrm{R} \& \mathrm{D}$ activity in rather isolated niche markets. This corresponds with a distinct feature of Italian groups, namely that they are made up of small and medium sized firms, which tend to serve niche rather than mass markets (Filatotchev et al. 2003). The notion that innovative activities in Italian manufacturing concentrate on relatively small markets is also supported by the fact that products that are new to the Italian market constitute only $3.8 \%$ of total manufacturing turnover (Evangelista et al. 1997). From a policy viewpoint, these results suggest that, although the apparently low substitutability of product innovations is connected to higher R\&D investments in coordinated activities, this comes at the price of lower R\&D efficiency. The integration and joint coordination of formerly independent R\&D activities should therefore be considered with care.

Positive externalities in process $\mathrm{R} \& \mathrm{D}$ indicate relatively high technological spillovers in this type of innovation. This corresponds to earlier findings that, particularly in Italian smaller firms, innovations processes are often informal and hence less protected, even when firms operate within groups (de Marchi and Rocchi 2000). Combined with the fact that the Italian industry is traditionally specialised in 'mature' technologies (de Marchi and Rocchi 2000; Evangelista et al. 1997), where process R\&D is prominent, relatively high spillovers (positive externalities) in this type of innovative activity are likely. Our results suggest that the internalization of such spillovers relate to a higher level of process $R \& D$ in coordinated efforts. However, we also find that process $R \& D$ in groups is less efficient than independent research. If internalization and coordination is the answer to spillovers, then, from a policy perspective, it is important to note that the costs and benefits of decreasing spillovers in process R\&D (e.g. through more effective knowledge protection) may be offset by changes in efficiency.

The fact that we do not find a significant difference in the ratio of product versus process $R \& D$ indicates similar slopes of the marginal $R \& D$ cost functions. As the Italian industry is rather mature, and as we are analysing a sample that averages all Italian manufacturing industries in various stages of their technological life cycles, 
this result is not surprising. It does, however, point towards an interesting avenue for further research. Industry specific analyses may provide deeper insights into the dynamic aspects of the role of externalities, particularly as Klepper (1996) suggests that we should observe different levels of opportunities in product versus process improvements over the evolution of an industry.

Acknowledgments The authors wish to thank Rob Alessie, Karen Klomp, Hans Schenk, the participants at the ECIS seminar, Eindhoven University, March 2005, at the EARIE Conference, Porto, Portugal, 1-4 September 2005, and at the 2nd IASTED International Conference on Alliances, Mergers and Acquisitions, MIT, Cambridge, MA, USA, 8-10 November 2004, for helpful comments and suggestions. This work has been accomplished with the cooperation of the Italian Statistical Office (ISTAT) and in particular of Andrea Mancini and Roberto Monducci, whose collaboration made this work possible. The research has been supported by the University of Bergamo (Elena Cefis, grant ex 60\% n.60CEFI07, Department of Economics)

Open Access This article is distributed under the terms of the Creative Commons Attribution Noncommercial License which permits any noncommercial use, distribution, and reproduction in any medium, provided the original author(s) and source are credited.

\section{References}

Abernathy WJ, Utterback JM (1979) Patterns of industrial innovation. Technol Rev 80:41-47

Abernathy WJ, Utterback JM (1982) Patterns of industrial innovation. In: Tushman ML, Moore WL (eds) Readings in the management of innovation. Pitman, Boston, pp 97-108

Adams JD, Marcu M (2004) R\&D sourcing, joint ventures and innovation: a multiple indicators approach, NBER 10474

Agarwal R, Audretsch DB (2001) Does entry size matter? The impact of the life cycle and technology on firm survival. J Ind Econ 1:21-43

Ahuja G, Katila R (2001) Technological acquisitions and the innovation performance of acquiring firms: A longitudinal study. Strat Manage J 22:197-220

Amir R, Evstigniev I, Wooders J (2003) Noncooperative R\&D and optimal R\&D Cartels. Games Econ Behav 42:183-207

Allen JW, Phillips GM (2000) Corporate equity ownership, strategic alliances, and product market relationships. J Finance 55(6):2791-2815

Anderson P, Tushman M (1990) Technological discontinuities and dominant designs: a cyclical model of technological change. Adm Sci Quart 35:604-633

Bartoloni E, Baussola M (2001) The determinants of technology adoption in Italian manufacturing industries. Rev Ind Organ 19(3):305-328

Bartoloni E, Baussola M (2008) The persistence of profits, sectoral heterogeneity and firms' characteristics. Int J Econ Bus (forthcoming)

Blonigen B, Taylor C (2000) R\&D activity and acquisitions in high technology industries: evidence from the US electronics industry. J Ind Econ 47(1):47-71

Bonnano G, Haworth B (1998) Intensity of competition and the choice between product and process innovation. Int J Ind Organ 16:495-510

Brouwer E, Kleinknecht A (1999) Innovative output, and a firm's propensity to patent. An exploration of CIS micro data. Res Policy 28:615-624

Cassiman B, Colombo M, Garrone P, Veugelers R (2003) The impact of M\&A on the R\&D process. An empirical analysis of the role of technological and market relatedness, mimeo

Cassiman B, Veugelers R (2002) R\&D cooperation and spillovers: some empirical evidence from Belgium. Am Econ Rev 92(4):1169-1184

Cohen W, Levin R (1989) Empirical studies of innovation and market structure. In: Schmalensee R, Willig R (eds) Handbook of industrial organisation, Chap. 18. North-Holland, Amsterdam, pp 1060-1107

Crosato L, Ganugi P (2007) Statistical regularity of firm size distribution: the pareto IV and truncated yule for Italian SCI manufacturing. Stat Methods Appl 16(1):85-115 
D'Aspremont C, Jacquemin A (1988) Cooperative and noncooperative R\&D in duoploy with spillovers. Am Econ Rev 78:1133-1137

De Bondt R (1996) Spillovers and innovative activities. Int J Ind Organ 15:1-28

De Bondt R, Veugelers R (1991) Strategic investment with spillovers. Euro J Polit Econ 7:345-366

de Marchi M, Rocchi M (2000) Basic research in Italian industry. R\&D Manage 30(1):79-88

Duranton G (2000) Cumulative investment and spillovers in the formation of technological landscapes. J Ind Econ 2:205-213

Eswaran M, Gallini N (1996) Patent policy and the direction of technological change. RAND J Econ 27:722-746

Eurostat (2003) Meeting of the Working Party on Science, Technology and Innovation (STI) Statisticse, Luxembourg

Filatotchev I, Piga C, Dyomina N (2003) Network positioning and R\&D activity: a study of Italian groups. R\&D Manage 33(1):37-48

Evangelista R, Perani G, Rapiti F, Archibugi D (1997) Nature and impact of innovation in manufacturing industry: some evidence from the Italian innovation survey. Res Policy 26:521-536

Evangelista R, Immarino S, Mastrostefano V, Silvani A (2002) Looking for regional systems of innovation: evidence form the Italian innovation survey. Reg Stud 36(2):173-186

Gugler P, Siebert R (2004) Market power versus efficiency effects of mergers and research joint ventures: evidence from the semiconductor industry, NBER Working Paper 10323

Hagedoorn J, Cloodt M (2003) Measuring innovative performance: is there an advantage in using multiple indicators? Res Policy 32:1365-1379

Hall B (1990) The impact of corporate restructuring on industrial research and development, Brookings Papers on Economic Activity

Hall B (1999) Mergers and R\&D revisited, mimeo

Hinloopen J (2003) R\&D efficiency gains due to cooperation. J Econ 80(2):107-125

Hitt MA, Hoskisson RE, Ireland RD, Harrison JS (1991) Effects of acquisitions on R\&D inputs and outputs. Acad Manage J 34(3):693-706

Hitt M, Hoskisson R, Johnson R, Moesel D (1996) The market for corporate control and firm innovation. Acad Manage J 39:1084-1119

Huber P (1967) The behavior of maximum likelihood estimates under non-standard conditions. In: Proceedings of the fifth Berkeley symposium on mathematical statistics and probability, vol 1. University of California Press, Berkeley, pp 221-233

Kamien MI, Muller E, Zang I (1992) Research joint ventures and R\&D Cartels. Am Econ Rev 82:12931306

Katz ML, Shelanski HA (2004) Merger policy and innovation: must enforcement change to account for technological change? NBER Working Paper 10710

Kleinknecht A, van Montfort K, Brouwer E (2002) The non-trivial choice between innovation indicators. Econ J Innovat New Technol 11(2):109-121

Kleinknecht A (ed) (1996) Determinants of innovation: the message from new indicators. Macmillan, London

Klepper S (1996) Entry, exit, and innovation over the product life-cycle. Am Econ Rev 86:562-583

Klepper S, Graddy E (1990) The evolution of new industries and the determinants of market structure. RAND J Econ 21(1):27-44

Mairesse J, Mohnen P (2002) Accounting for innovation and measuring innovativeness: an illustrative framework and an application. Am Econ Rev 92:226-231

Miller D, Friesen P (1986a) Porter's (1980) Generic strategies and performance: an empirical examination with American data. Part I: Testing Porter. Organ Stud 7:37-56

Miller D, Friesen P (1986b) Porter's (1980) Generic strategies and performance. Part II: Performance implications. Organ Stud 7:255-261

OECD (1997) Proposed guidelines for collecting and interpreting technological innovation data: the "Oslo" Manual. Organisation for Economic Development and Co-operation, Paris

Pavitt K (1984) Patterns of technical change: towards a taxonomy and a theory. Res Policy 13(6):343-373

Piga CA, Vivarelli M (2004) Internal and external R\&D: a sample selection approach. Oxford Bull Econ Stat 66(4):457-482

Porter ME (1980) Competitive strategy. The Free Press, New York

Ravenscraft DJ, Scherer FM (1987) Mergers, sell-offs, and economic efficiency. The Brookings Institution, Washington 
Röller L-H, Stennek J, Verboven F (2001) Efficiency gains from mergers. Euro Econ 5:31-128

Rosenkranz S (2003) Simultaneous choice of process and product innovation when consumers have a preference for product variety. J Econ Behav Organ 50:183-201

Salant SW, Shaffer G (1999) Unequal treatment of identical agents in Cournot equilibrium. Am Econ Rev 89:585-604

Scarpetta S, Bartelsman E, Bassanini A, Haltiwanger J, Jarmin RS, Schank T (2004) The spread of ICT and productivity growth: is Europe really lagging behind in the new economy? In: Cohen D, Garibaldi P, Scarpetta S (eds) The ICT revolution: productivity differences and the digital divide: a report for the Fondazione Rodolfo Debenedetti. Oxford University Press, Oxford, pp 1-112

Scherer FM (1992) Schumpeter and plausible capitalism. J Econ Lit 30:1416-1433

Sirilli G, Evangelista R (1998) Technological innovation in services and manufacturing: results from Italian surveys. Res Policy 27:881-899

Suarez F, Utterback J (1991) Dominant designs and the survival of firms, Sloan School of Management. MIT, Working Paper, pp 42-91

Tushman M, Anderson P (1986) Technological discontinuities and organization environments. Adm Sci Quart 31:439-465

Villalonga B, McGahan AM (2005) The choice among acquisitions, alliances, and divestitures. Strat Manage J 26:1183-1208

White H (1980) A heteroskedasticity-consistent covariance matrix estimator and a direct test for heteroskedasticity. Econometrica 48:817-838

Yin X, Zuscovitch E (1998) Is firm size conducive to R\&D choice? A strategic analysis of product and process innovations. J Econ Behav Organ 35:243-262 